Proceedings

\title{
Images Narrating Places ${ }^{\dagger}$
}

\section{Giovanna A. Massari}

Department of Civil Environmental and Mechanical Engineering, University of Trento, 38123 Trento, Italy; giovanna.massari@unitn.it; Tel.: +39-0461-282644

+ Presented at the International and Interdisciplinary Conference IMMAGINI? Image and Imagination between Representation, Communication, Education and Psychology, Brixen, Italy, 27-28 November 2017.

Published: 6 December 2017

\begin{abstract}
The reflections set out in the following pages offer a possible answer to the question "what do images do?" in relation to the remit of architecture and the field of restoring architectural heritage. We shall consider the ways in which the perception of images for certain installations, as also their contents, created for exhibitions in two Austro-Hungarian fortresses, may influence the actions of the observer at several levels. We shall set out to describe how such results can depend on various factors: the material props and mapping techniques, the greater or lesser recognisability of the object represented, the type of transposition for $3 \mathrm{D}$ reality to $2 \mathrm{D}$ representation and the relations between transmission techniques and degrees of comprehension.
\end{abstract}

Keywords: agency; architecture of fortifications; digital representation; graphic communication; Habsburg Empire; museum installations; virtual reconstruction; visual simulation

\section{Introduction}

Number 17-18 of the magazine Lexia, published in 2014, and dedicated to the question of "Efficacious images", contains various ideas on the "agency" of images, namely «their capacity to orientate, encourage or even induce action on the part of the observer in terms of cognition and epistemology (inducing understanding), pragmatics (inducing action), emotion (eliciting states of being)» [1] (p. 11). In the preface to this number he edited, Massimo Leone posited the central question: what do images do? What elements determine their behaviour and influence, «the passage from the reception of a visual text to the preparation/execution of a practice or even a form of being»? How, in other words, can the perception of images and contents of visual experience influence the way they operate in the world?

The two projects illustrated in the following pages address this kind of problem, with regard to the professional fields of architecture and the restoration of architectural heritage, and referring specifically to the fitting out of museum areas inside historical buildings. Images are, therefore, deployed insofar as "representations" bound by "educational" needs in their widest sense-in other words they are used as an information vehicle to communicate something separate from themselves, i.e., excluding the meaning attaching to figurative appearance of a thing in itself and its exterior autoreferential form. The relationship that images establish with the real context in which they are situated is "necessary". It is a deeply rooted relationship even if the images are displayed in virtual space obtained by the use of advanced tools for the transmission of messages. The reference to the architectural setting will remain the main reference for the interaction between the image, which constructs narrative paths, and the observer involved, if the visual product is sufficiently developed to stimulate the imagination rather than simply to astound and excite marvel.

The images of the architectural works and landscapes that accompany the text indicate a precise design choice, related, as it is, to forms of communication that can exploit a close link between the form and idea of physical space. However, the "efficacy" of the results depends, in both the cases in 
question, on various factors: the conditioning inherent in the material props and the methods of mapping and perception; the iconic nature and the recognisability or otherwise of the object represented; the type of transposition from the real world to the prop or support used, whether or not projective, fixed or animated; and, in conclusion, the relationship created between techniques of transmission and/or reception and the possibilities of understanding and/or interpretation.

\section{Images and Architectural Space}

The use of digital technology has exponentially increased the "things that can be done with images" in the fields of architecture and museums: virtual reality, augmented reality, $3 \mathrm{~d}$ mapping are only some of the most well-known solutions used to disseminate knowledge, attract attention, improve a service, encourage participation, define a product and much else besides.

Here, we would like to limit the field to images that describe precise episodes of an artefact's use and their visual communication capabilities in the enclosed spaces of historical buildings: whether isolated or in series, self-sufficient or dependent upon forms and signs of the surrounding environment. In particular, we shall discuss images that constitute permanent or temporary collections of civic, historic, archaeological and ethnographic museums but we shall refrain from discussing the personality or skills of their author or the designer of the installations. Instead, such images will be considered as the expression of the will to focus attention on the visitors of the "geohistory" of the places and events narrated, whether contemporary or in the distant past.

The waywardness of contemporary life requires that such images lend themselves to being rapidly consumed, but the speed with which the divulged message is proposed must also respect the qualities of form and content necessary for an educational message to be correctly transmitted. Every image is really a hybrid and exploits a mix of universal and cultural languages, in other words those communicative modes that Pierce called "hypo-icon", i.e., elements comprising both "icons" and "index likenesses" [2] (p. 11). However, whether immediately analogical or pregnant with cultural meaning, whether faithful or not to the perceived reality they return, images must, in educational exhibitions, succeed in stimulating the observer's imagination so that he or she will stop to engage that "slow", critical gaze that constitutes an essential premise for any social improvement.

The experience of architectural space and that of the image as an "exhibition product" can thus come together at ever-growing levels of complexity where the visual component can, through the essential dimension of the "apparition" test the limits of our understanding and knowledge [3] (pages 56-57). An understanding triggered by direct "aesthetic-empirical" experience, and aroused by the simple fact that a work is before our eyes, undergoes a successive phase of mediated and "deferred" experience that can go beyond the possible absence of the work, in order to achieve an extensive "critical-relational" type experience [4].

Time, not space, therefore, becomes the real protagonist: the time an observer spends before a work and where it is housed, and the timeline referred to by the image and before which «the observer must not only ask himself what history is being documented and its contemporary reference, but also what deep-seated and perhaps buried "memory" the image connotes» [3] (p. 65).

\section{Forte Corno: Images and Material}

The multimedia installations of Forte Corno represent the first example of the transposition of the foregoing reflections into a concrete design project.

Forte Corno belongs to the third generation of forts built in Trentino by the Austro-Hungarian Empire, the so-called mountain forts or Gebirgsfort; designed and built between 1883 and 1890. At a height of over $1000 \mathrm{~m}$, the fort dominates the landscape of the high valley of the Chiese [5] (Figure 1). The architecture documents in an exemplary manner the time of the transition from the first military buildings, characterised by formal and compositional refinements, to the last reinforced fortresses, which employed new construction and functional rules. The fort comprises five levels, each partially excavated in the mountain with a clear separation between the top floors, assigned to the quarters and services for the troops and the lower levels comprising the premises for heavy pieces of artillery. The fort was never operational: by 1915 it had been decommissioned and disarmed, and in the 
following decades underwent rapid decay on account of such natural and anthropic causes as the infiltration of water, the growth of weeds and shrubs, structural failures, and the removal of iron sections, wooden ceilings and flooring.

Forte Corno, which was bought by the local municipality in 2000, between 2003 and 2014, underwent careful restoration thanks to financing provided by the Autonomous Province of Trento for the First World War Project [6]. Its structures were consolidated, electrical wiring installed, the access bridge and the look-out turret were reconstructed, the external appurtenances were refurbished and, first and foremost, a zinc-titanium sheet roof was built to protect a building that every year attracts thousands of visitors.

In the framework of the initiatives for the commemoration of the centenary in 2013 the municipality of Praso requested the University of Trento to design a permanent installation for a multimedia visitor-itinerary. The research group proposed an itinerary centring upon a few "enticing" nodes where advanced digital communication and audio-visual contents could be deployed to describe the geographical location of the bellicose events that took place around the fortified barrier of Lardaro and the correlated Hapsburg defensive structures.
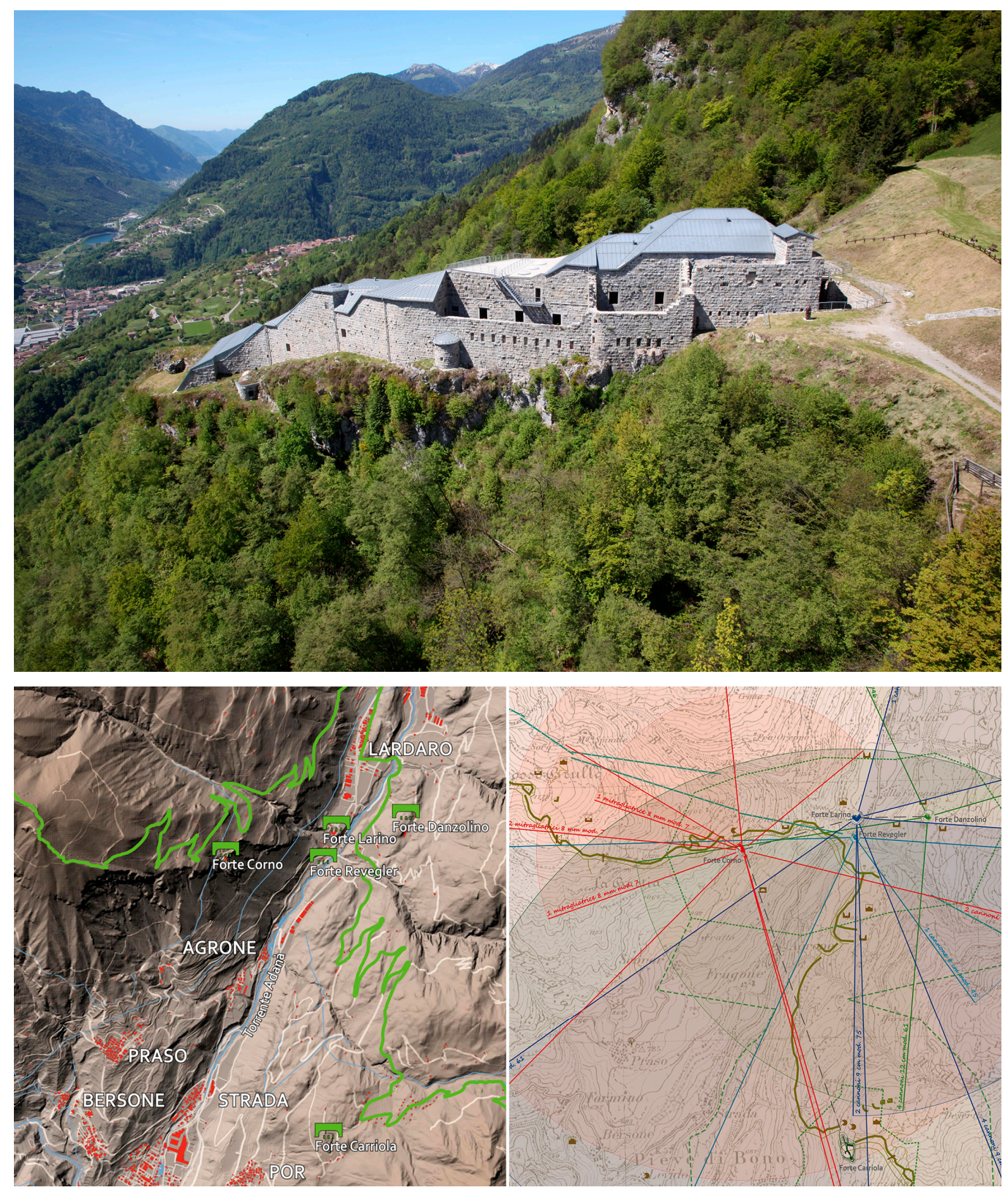

Figure 1. Above, the aerial view of Forte Corno; down, the five Hapsburg forts of the fortified barrier of Lardaro in the valley of the Chiese. 
The spirit animating the entire project proposes images that seem to materialise from the walls themselves to relate the fort's history and strategic role. It is as if the stones had come to life to narrate what befell the fort, visually evoking memories of the past, and in so doing they become a message for the present. The installation aims at dissociating the perception of the material physicality of its stone envelope, whose rugged presence defines the various environments, from the perception of images that narrate what took place therein, and reliving the human tensions involved, within the framework of the historical and geographical context of the peoples that lived in the decades prior to the conflict. The objective is to give life to complex reflections, generated by the mental synthesis of two direct images of reality, physically connected but strongly distinct for their visual quality. The rugged, heavy and impenetrable walls of the spaces hosting the observer, on the one hand, and ethereal, light and luminous exhibition objects that constitute the museum installations and transmit its contents, on the other.

The design plan is based upon the desire not to compromise the free perceptibility of the architectural spaces or create functional conflicts with the pre-existing structures whose suggestive aspect remain practically unaltered from the time of its abandonment. The design does not attempt the impossible task of camouflaging the fort's strong personality by direct projections onto the walls or distributing installations throughout the environments. Instead, the design is easily recognised and separated from its surrounding in terms of materials, forms, colours and positions (Figure 2).

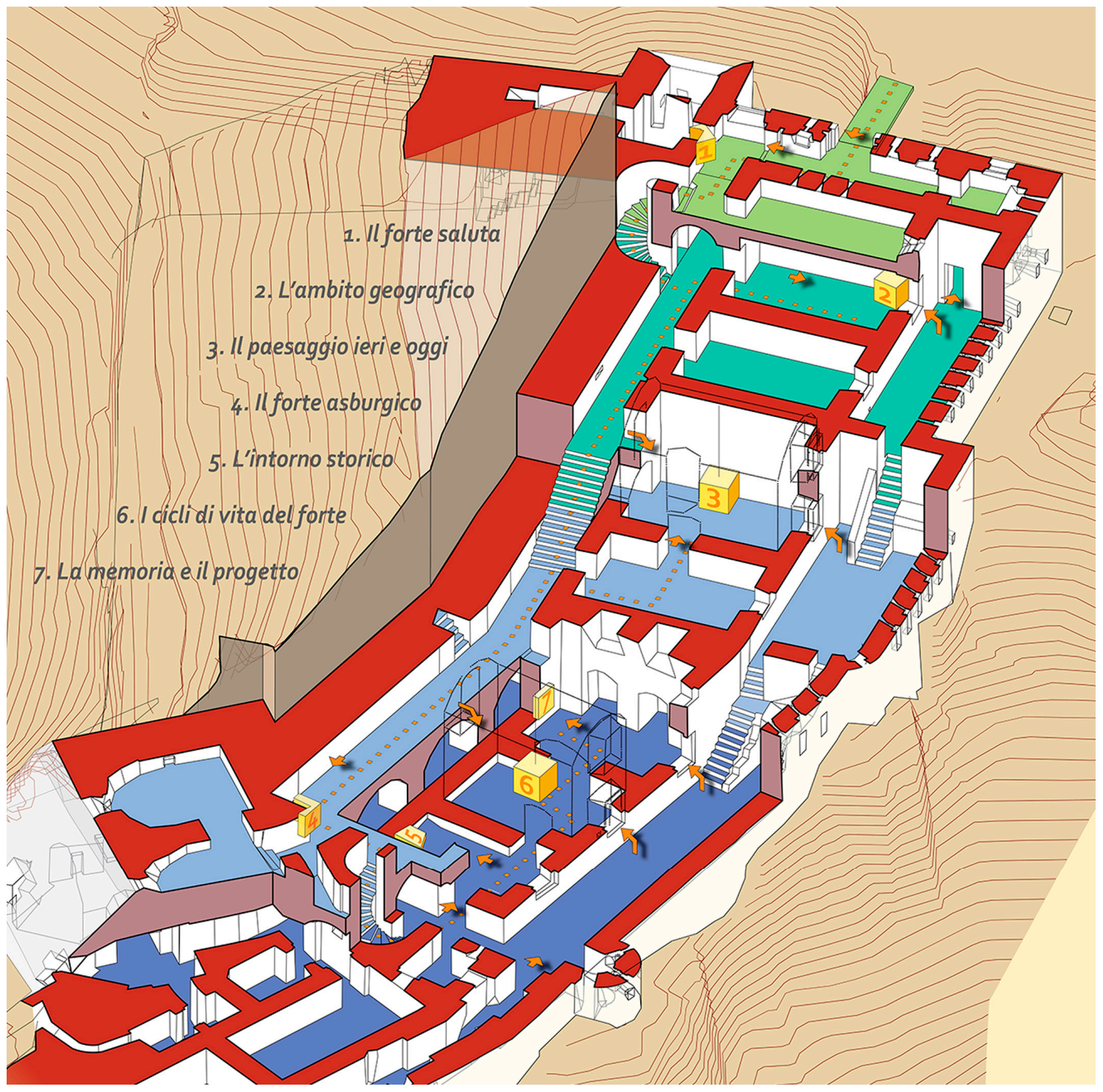

Figure 2. The multimedia tour of Forte Corno. 
Images, footage and texts are provided as comments and explanation but at a different level of communication with respect to their historical surroundings. In other words, the illustration does not compete with nor confound itself with the architecture being illustrated (Figure 3).
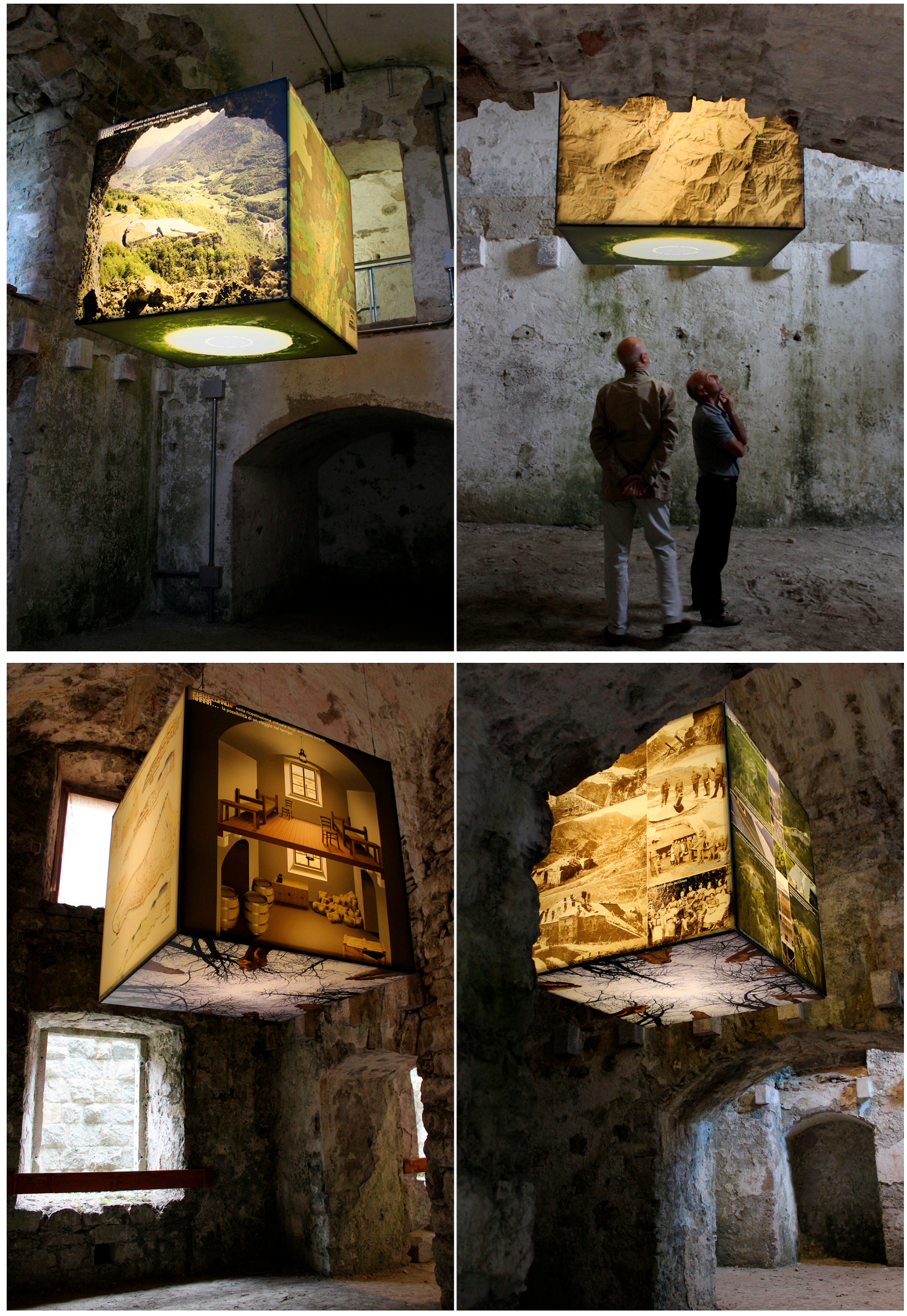

Figure 3. The exhibition design in the interiors of Forte Corno. 
The installation, inaugurated in the summer of 2014, consists in the inclusion of pure and luminous cubes in combination with and enhancing guided tours of the fort. The cubes are arranged as outgrowths extruding in various degrees from the walls, as the "crystallisation" of matter, and which in the larger environments succeed in liberating themselves, as though they were magically suspended in space. At this point the exhibition reaches its maximum level of abstraction.

The seven cubes leave the fort's authenticity and extraordinary atmosphere intact as they define a succession of moments, immediately recognisable and connected by an autonomous logical storyline, emerging from an independent stereo-metric geometry. Their faces offer the pages of a multimedia narration, and all the information to be provided is set out as if it belonged to "another" space, temporarily external to the fort itself. The frames are in galvanized aluminium, while the panels dedicated to static images are made from pre-printed thermo-stretched Barrisol sheeting, and retro-lit with a "Strip Led" system. The panels with dynamic content, instead, incorporate Samsung monitors.

Today's visitor to Forte Corno will find images illustrating its structure and use and its relations with the territory, as well as a representation of the surrounding landscape and its current values, in environmental and human terms, of what was once one of the main theatres of war. In this manner, Forte Corno narrates its history, as well as that of its territory and its people.

\section{Roncogno Battery: Images and Structure}

The second design project refers to the Roncogno Battery or Fort, which was once part of the fortified system built by the Austro-Hungarian Empire to defend the city of Trento. It was built between 1879 and 1880 on a natural terrace at $805 \mathrm{~m}$ in height at the base of Mt. Celva, to control the access to the Adige valley from the Valsugana through the Cimirlo pass which at that time was called the Sella di Roncogno.

The defensive system comprised exposed and protected artillery pieces, in respectively "barbette" and "casemate" positions (Figure 4). The latter were housed in a building made from squared ashlars, with a single level horseshoe layout. It was divided into four main spaces, where the soldiers were quartered and the cannons were situated, two smaller premises that housed the commander's quarters, the rooms reserved for the ammunition and foodstuffs and a kind of "pillbox" where the toilet facilities and kitchen were situated. The fort could host a garrison of no more than one officer and 32 soldiers. It was modernised in 1904 and its armaments renewed. However, in 1915 it was disarmed and abandoned as the fort's design no longer met the military requirements of the day. The four cannons were taken to new positions in a cave along the ridge of Mt. Celva, an important stronghold whose fortifications are mostly still visible today. After 1915, Roncogno Battery was occasionally used as a depot.

In the post-war, the building was acquired by the municipality of Trento and has recently been incorporated in a large-scale project as part of a territorially distributed museum to record the First World War promoted by the Autonomous Province of Trento in 2009. The restoration work, which began in 2010, fully respected the original construction typology, the size and volumes. The roof was refurbished with a wooden structure and cladded with porphyry slabs, the walls were consolidated, and the trenches and Austro-Hungarian walkways were cleaned [7].

In May 2016, the municipality entrusted the management of the fort to the Scout Section of Trento of the CNGEI (the National Association of Young Italian Explorers), in cooperation with the Trentino Historical Museum Foundation and the University of Trento to promote knowledge of the fort. A research group was formed to study the internal environments for an installation compatible with the performance of socio-cultural and recreational activities.

The solution chosen makes use of permanent supporting structures and movable information panels that can be used for both guided tours or as supports for the various needs of temporary exhibitions. The exhibition space proposed by the design project, and currently under construction, is characterised by its thematic homogeneity even if occupying only three of the eight large alcoves of the fort's four main environments. 

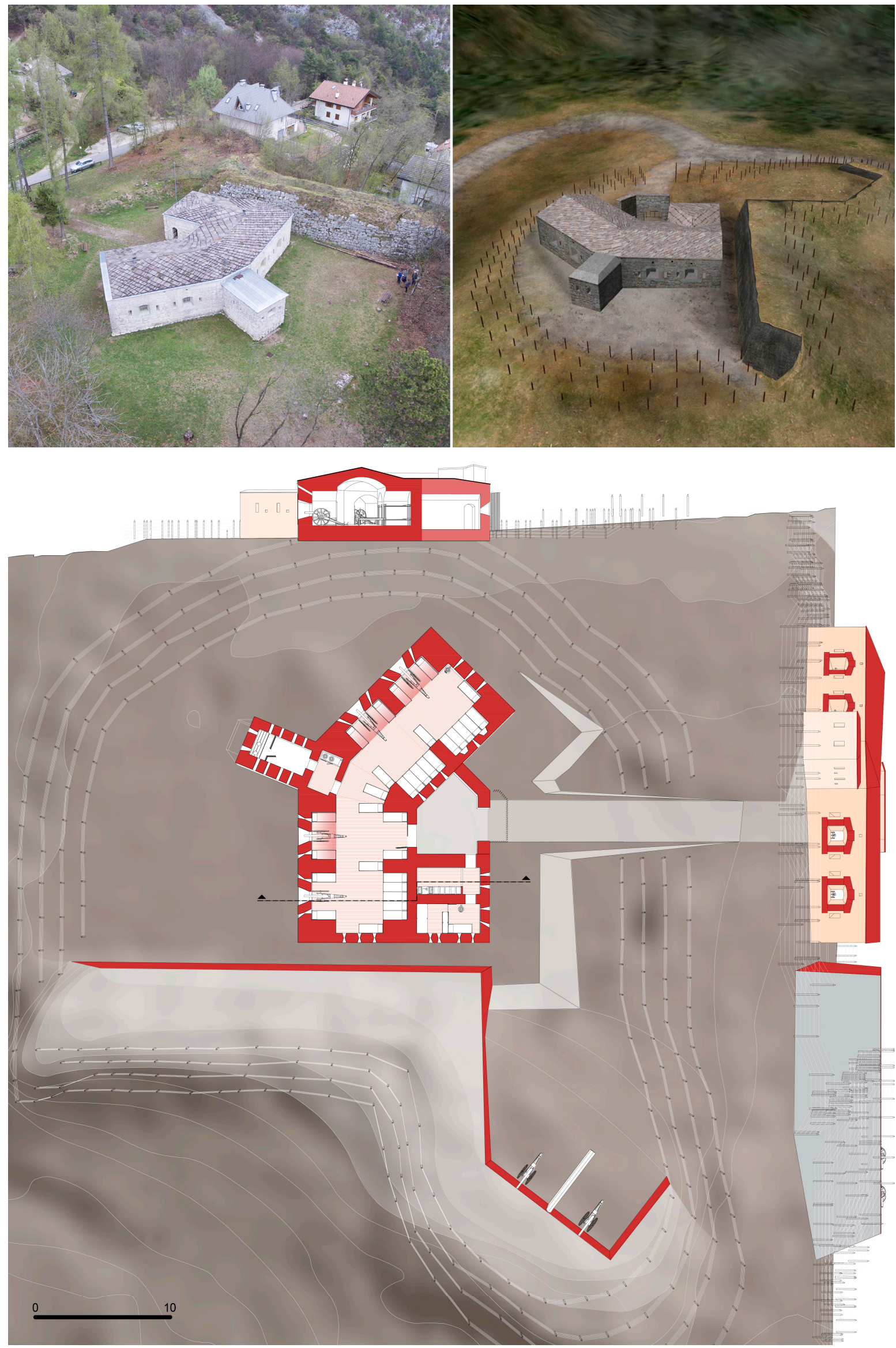

Figure 4. Above, the aerial view and virtual reconstruction of Roncogno Battery; down, the graphic reworking of the Hapsburg project drawings: the three exhibition areas are highlighted on the map. 
The effect of unity in space is obtained by linking the barrel roofs of the alcoves and the corresponding surfaces of the walls and floors with the same sign that makes visitors perceive each room as part of a single round tunnel: the supporting structures carry both the panels, of varying sizes and curvatures, and the lighting system. The ease of identifying the three sectors of the tunnel in terms of form and vicinity guarantees that they are immediately perceived as a whole as well as being distinguished by slightly raised platforms on which three thematic maps of the surrounding territory are depicted: three representations on the same scale of the same geographical environment but referring to three different historical eras (Figure 5).

The first map illustrates the landscape in 1885, a few years after the fort's construction and comprises a carefully designed mosaic of military maps originally on a scale of 1:5000. On the walls above the map, the relationship between the battery or fort and territory is depicted, including the range of the cannons and rifles and the area covered by visual control.
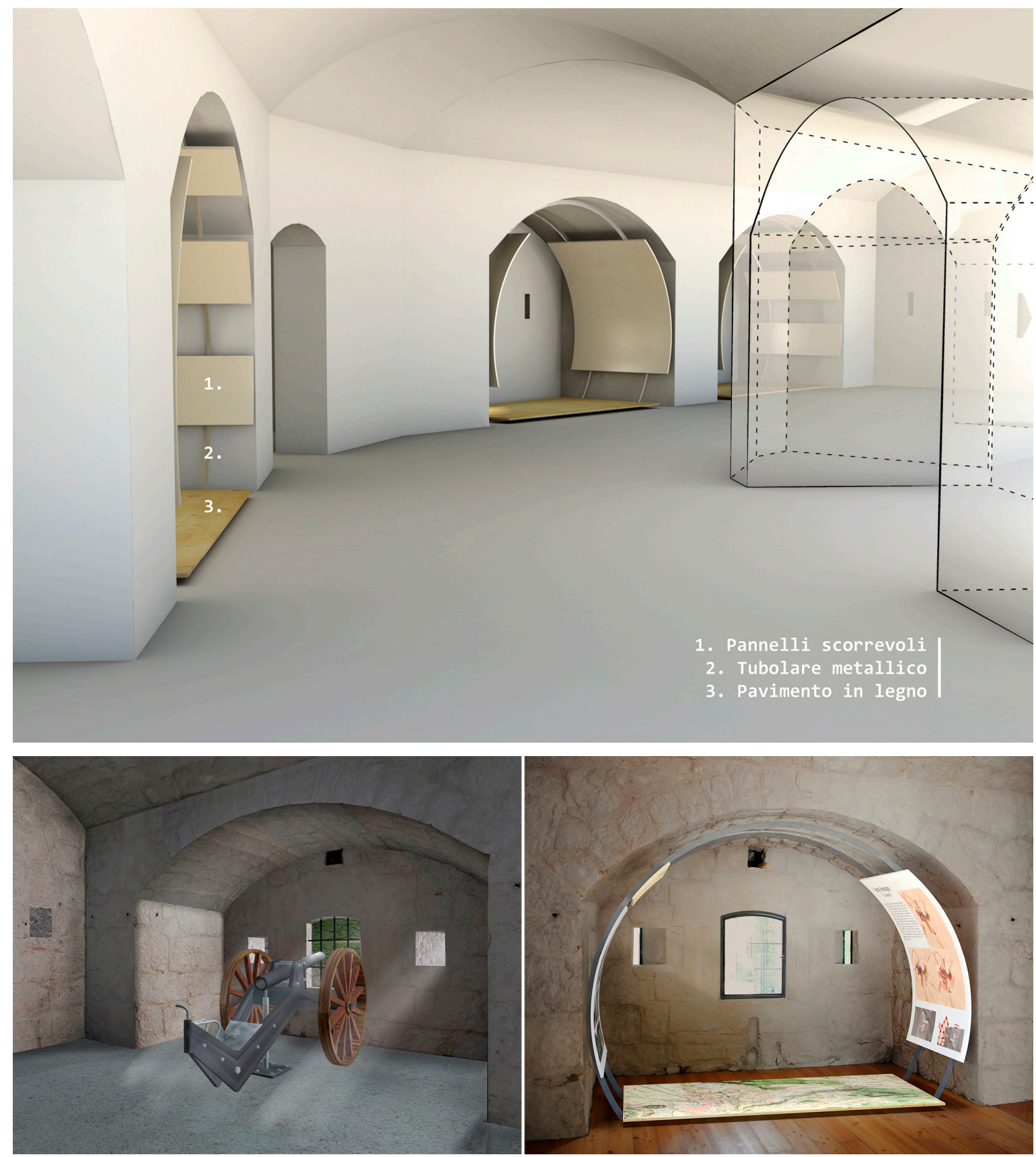

Figure 5. Above, the proposed exhibition design in the "casemate" of Roncogno Battery; down, the virtual reconstruction and design simulation of one of the cannons' placements. 
The second map illustrates the natural and anthropic context in 1914, the year the conflict commenced in Trentino, and provides a sky-view of a digital model of the territory in tonalities of grey prepared using Lidar (Laser Imaging Detection and Ranging) data. The panels along the roof illustrate the life in the fort during the period when it was active, using virtual reconstruction images. The third map illustrates the present situation based on an orthophoto map produced using AGEA 2011 (Agency for Agricultural Funding) data. On the roof there are the images of the years when the fort was abandoned and the restoration worksite. Three sky views and three "thematic" windows that, therefore, attract the visitor and transport him for a "brief" visit of just over one hundred years.

\section{Conclusions}

The installation created for Forte Corno and that proposed for the Roncogno Battery are both based on the idea that exhibition images cannot be freely moved insofar as each is conceived for a definite architectural space: the stones from which variously placed cubes emerge in the first case, and surfaces of the barrel-vaulted rooms covered with panels of varying sizes, in the second. Notwithstanding the exclusive use of images produced by digital processing that increasingly lead us to forget their physical support, the two experiences discussed in these pages indicate how the characteristics of the support for an image are not of marginal importance with respect to an image's information content; some of such supports' components (morphological, dimensions, material) participate in an essential manner in the creation and transmission of the visual message [8].

A first factor to remember in terms of the relationship between an image and its prop or support, refers to the "disturbance" deriving from the interference between the material (sheets, canvas, wall, screen, etc.) and the object of the representation: sometimes the message is almost hidden by the background noise created by the material that transmits it, while in other cases it clearly allows a message to be efficaciously transmitted by a surface that tends to disappear. To clarify the question, we can imagine the limiting case of an image roughly traced out with a stick on sand in comparison with a perfect projection, in terms of luminosity, realism and resolution of a subject illustrated on a large illuminated screen.

A second and a third factor, both closely related to the first, refer, respectively, to the "material quality" of the support and its "third dimension". Some substances actually have considerable power to make a representation realistic by simulating what they depict, so much so as to make it difficult to distinguish between the subject and its reproduction. The final effect is then influenced by the very nature of the signs that may be without width (neither in relief or etched) or in high or bas relief or also in the form of a light engraving.

The "frame" factor is, therefore, responsible for the influence produced by the form and above all by the size of the outline on the content of the image, while the "positioning" factor can condition the perceptive relationship with the observer according to the configuration and location of the support. Thus, there are many factors involved and the question would merit further analysis in critical and applicative terms in the course of future research, commencing from a synthetic analysis of the distinctive elements of the image as discussed herein.

Acknowledgments: Roberto de Rubertis conceived the exhibition installations and guided every aspect of the research, constantly stimulating ideas and actions. Cristina Pellegatta and Fabio Luce devised all the models and digital images today used in Forte Corno dedicating passion and attention to every detail; Michela Favero and Roberto Panelatti offered valuable advice in the designing of the itineraries for visiting the fort. Giuseppe Gorfer, Riccardo Giacomelli and Matteo Paoli dedicated considerable time and skill to the definition of the museum spaces in the Roncogno Battery; Giulio Giacomoni and the Trento Scout Section of CNGEI with great enthusiasm stimulated the project's promotion. The Superintendence for Cultural Heritage of the Autonomous Province of Trento, the Italian Historical War Museum of Rovereto and the Trentino Historical Museum Foundation sustained the collection and study of historical, archive and iconographic documents and maps with constant attention and cooperation.

Conflicts of Interest: the author declares no conflict of interest. 


\section{References}

1. Leone, M. (Ed.) Immagini Efficaci. Efficacious Images, Lexia 17-18; Aracne editrice: Ariccia, Italy, 2014; p. 771, ISBN 978-88-548-7680-4, ISSN 1720-5298-17.

2. Eco, U. La lingua imperfetta delle immagini. In La Forza Delle Immagini, 1st ed.; Eco, U., Augé, M., DidiHuberman, G., Eds.; Franco Angeli: Milan, Italy, 2015; pp. 9-29, ISBN 978-88-917-1130-4.

3. Didi-Huberman, G. La condizione delle immagini. In La forza Delle Immagini, 1st ed.; Eco, U., Augé, M., Didi-Huberman, G., Eds.; Franco Angeli: Milan, Italy, 2015; pp. 55-75, ISBN 978-88-917-1130-4.

4. Ugo, V. L'esperienza dell'opera. In I Luoghi di Dedalo, 1st ed.; Edizioni Dedalo: Bari, Italy, 1991; pp. 56-61, ISBN 88-220-6110-1.

5. Carrara, V.; Favero, M. Le Montagne Dei Forti, 1st ed.; Fondazione Museo Storico del Trentino: Trento, Italy, 2014; p. 160, ISBN 978-88-7197-175-9.

6. Dallavalle, M.; Favero, M.; Forte, C. Paesaggio in trasformazione. In Il recupero Dei Forti Austroungarici Trentini, 1st ed.; Dallemule, M., Flaim, S., Eds.; Provincia Autonoma di Trento: Trento, Italy, 2014; pp. 168185, ISBN 978-88-7702-379-7.

7. Gorfer, G. Il restauro della Batteria Roncogno a Passo Cimirlo. In Il Recupero Dei Forti Austroungarici Trentini, 1st ed.; Dallemule, M., Flaim, S., Eds.; Provincia Autonoma di Trento: Trento, Italy, 2014; pp. 186199, ISBN 978-88-7702-379-7.

8. Di Napoli, G. Il supporto: Superficie, velo e schermo. In Disegnare e Conoscere, 1st ed.; Giulio Einaudi Editore: Turin, Italy, 2004; pp. 187-201, ISBN 88-06-16752-9.

(C) 2017 by the authors. Licensee MDPI, Basel, Switzerland. This article is an open access article distributed under the terms and conditions of the Creative Commons Attribution (CC BY) license (http://creativecommons.org/licenses/by/4.0/). 